\title{
INEQUALITIES FOR POLYNOMIALS AND THEIR DERIVATIVES II
}

\author{
ARUN KUMAR VARMA*) \\ (Received October 16, 1966; revised February 13, 1967)
}

Introduction. Many theorems of the theory of approximation depend upon the fact that a polynomial of degree $n$ cannot change too rapidly; in other words its derivative cannot be too large. We know from A. A. Markov's inequality for polynomials that if $\left|P_{n}(x)\right| \leqq M$ on $[-1,1]$ then $\left|P_{n}^{\prime}(x)\right|$ $\leqq M n^{2}$ for $-1 \leqq x \leqq 1$ where $P_{n}(x)$ is an algebraic polynomial of degree $n$. But this is an extreme case. For special polynomials, one can sometimes improve the estimates of the derivative. For this we refer to papers of P. Erdös [4], G. Lorentz [8], and P. Turán [11].

1.1. In 1958 J. Balázs and P. Turán [3] obtained certain interesting inequalities which arise from their consideration of $(0,2)$ interpolation on $\pi$-abscissas $\left(\pi_{n}(x)=\left(1-x^{2}\right) P_{n-1}^{\prime}(x), P_{n}(x)\right.$ being the Legendre polynomial of degree $=n)$. By $(0,2)$ interpolation they mean the problem of finding interpolatory polynomials $R_{n}(x)$ of degree $\leqq 2 n-1$ for which

$$
R_{n}\left(x_{k}\right)=\alpha_{k}, \quad R_{n}^{\prime \prime}\left(x_{k}\right)=\beta_{k}, \quad k=1,2, \cdots, n,
$$

are prescribed. From this consideration they proved the following:

THEOREM 1.1.1 (J. Balázs and P. Turán). Let $n$ be even and further if we are given for a polynomial $Q_{2 n-1}(x)$ of degree $\leqq 2 n-1$

$$
\left|Q_{2 n-1}\left(x_{k}\right)\right| \leqq A, \quad\left|Q_{2 n-1}^{\prime \prime}\left(x_{k}\right)\right| \leqq B, \quad k=1,2, \cdots, n,
$$

then for $-1 \leqq x \leqq 1$ we have

$$
\left|Q_{2 n-1}(x)\right| \leqq \pi^{6} n A+\frac{\pi^{5} B}{n}
$$

and

*) The author acknowledges financial support for this work from the University of Alberta Post Doctral Fellowship (1966-67) and summer research institute of the Canadian Mathematical Congress (1967). Since September 16, 1967, on faculty of Department of Mathematics, University of Florida, Gainesville, Florida (U.S.A.). 


$$
\left|Q_{2 n-1}^{\prime}(x)\right| \leqq \pi^{8} n^{5 / 2} A+\pi^{5} B n^{1 / 2} .
$$

The appearance of the exponent $5 / 2$ in (1.1.4) is very significant. (1.1.3) gives the estimate of $Q_{2 n-1}(x)$ uniformly in $[-1,1]$, whereas (1.1.4) gives the estimate of $Q_{2 n-1}^{\prime}(x)$ uniformly in $[-1,1]$ which is far better than what one can obtain from Markov's inequality applied on (1.1.3). Moreover (1.1.3) and (1.1.4) are best possible in a certain sense explained there in. We mention for the sake of orientation as remarked by $P$. Turán and J. Balázs [4] that if in $[-1,1] f^{\prime \prime}(x)$ exists everywhere and $|f(x)| \leqq 1$, $\left|f^{\prime \prime}(x)\right| \leqq 1$ then we have $\left|f^{\prime}(x)\right| \leqq 2$ for $[-1,1]$. This has been proved after the first results of C. N. Moore and Hardy-Littlewood by E. Landau [7]. It would be of interest to point out that L. Fejér [6] in 1930 obtained the following result. Let $g(x)$ be an arbitrary polynomial of degree $\leqq 2 n-1$ satisfying

$$
\left|g\left(x_{i}\right)\right| \leqq A, \quad\left|g^{\prime}\left(x_{i}\right)\right| \leqq B, \quad i=1,2, \cdots, n,
$$

then uniformly in $[-1,1]$ we have

$$
|g(x)| \leqq A+B
$$

Here $x_{i}$ 's are the zeros of $T_{n}(x)=\cos n \theta, \cos \theta=x$ and $x_{i}=\cos \theta_{i}, \theta_{i}=\frac{(2 i-1) \pi}{2 n}$.

1.2. The object of this paper is to obtain analogous results when $x_{k}$ 's are taken to be the zeros of $\left(1-x^{2}\right) u_{n}(x), u_{n}(x)$ being the Tchebycheff polynomials of the second kind. We prove the following:

THEOREM 1.2.1. Let $Q_{2 n+1}(x)$ be an arbitrary polynomial of degree $\leqq 2 n+1$ ( $n$ even) satisfying

$$
\left|Q_{2 n+1}\left(x_{k}\right)\right| \leqq A, k=1,2, \cdots, n+2
$$

and

$$
\left|Q_{2 n+1}^{\prime \prime}\left(x_{k}\right)\right| \leqq \frac{B}{1-x_{k}^{2}}, \quad k=2,3, \cdots, n+1
$$

Then for $-1 \leqq x \leqq 1$ we have

$$
\left|Q_{2 n+1}(x)\right| \leqq c_{1}\left(A n^{3 / 2}+B n^{-1 / 2}\right), \quad\left(c_{1}=57\right)
$$

and

$$
\left|Q_{2 n+1}^{\prime}(x)\right| \leqq c_{2}\left(A n^{3}+B n\right), \quad\left(c_{2}=108\right)
$$


First we remark that the result (1.2.3) and (1.2.4) are essentially best possible, i.e., we can find suitable polynomials $f_{0}(x)$ and $f_{1}(x)$ of degree $\leqq 2 n+1$ which satisfies (1.2.1) and (1.2.2) and for a numerical positive $c_{3}$ and $c_{4}$, we have

$$
\left|f_{0}(0)\right|>c_{3}\left(A n^{3 / 2}+B n^{-1 / 2}\right),
$$

and

$$
\left|f_{1}^{\prime}(1)\right|>c_{4}\left(A n^{3}+B n\right) \text {. }
$$

Here $x_{k}$ 's mentioned in (1.2.1) and (1.2.2) are the zeros of $\left(1-x^{2}\right) u_{n}(x)$ given by

$$
1=x_{1}>x_{2}>\cdots>x_{n+1}>x_{n+2}=-1 \text {. }
$$

Thus comparing the results on these two abscissas we find that (1.2.3) and (1.2.4) are not as good as (1.1.3) and (1.1.4) although (1.2.3) and (1.2.4) are proved to be best possible as explained above. But there is a common feature between these two theorems, namely the growth of their derivatives are of the order $n^{3 / 2}$. If we apply Markov's theorem to (1.2.3) we will get

$$
\left|Q_{2 n+1}^{\prime}(x)\right| \leqq c_{1}\left(A n^{7 / 2}+B n^{3 / 2}\right) \text { in }-1 \leqq x \leqq 1
$$

From this we may conclude that the result stated in (1.2.4) is far better from (1.2.7) what we can obtain from Markov's theorem. For other interesting inequalities of the author when nodes of interpolation are taken as the zeros of $\left(1-x^{2}\right) T_{n}(x), T_{n}(x)$ being the Tchebycheff polynomials of the first kind we refer to [12].

1.3. In an earlier work [14] we proved that for $n$ even there exists a unique polynomial $R_{n}(x)$ of degree $\leqq 2 n+1$ for which

$$
\begin{aligned}
& R_{n}\left(x_{i}\right)=a_{i}, \quad i=1,2, \cdots, n+2, \\
& R_{n}^{\prime \prime}\left(x_{i}\right)=b_{i}, \quad i=2,3, \cdots, n+1,
\end{aligned}
$$

are prescribed in advance. Here as mentioned earlier

$$
1=x_{1}>x_{2}>\cdots>x_{n+1}>x_{n+2}=-1
$$

are the zeros of the polynomial $\left(1-x^{2}\right) u_{n}(x)$. We denote 


$$
R_{n}(x)=\sum_{k=1}^{n+2} a_{k} r_{k}(x)+\sum_{k=2}^{n+1} b_{k} \rho_{k}(x) \quad(n \text { even })
$$

where the fundamental polynomials $r_{k}(x)$ and $\rho_{k}(x)$ are stated in Theorem 2.1.1.

We now consider the sequence of points

$$
1=x_{1, n}>x_{2, n}>\cdots>x_{n+1, n}>x_{n+2, n}=-1
$$

where $x_{k, n}$ 's stand for the zeros of $\left(1-x^{2}\right) u_{n}(x)$. (The notation (1.3.3) of the zeros $\left(1-x^{2}\right) u_{n}(x)$ was more suitable when $n$ was fixed). Then forming the interpolatory polynomials (1.3.4) satisfying (1.3.1) and (1.3.2) for each $n=2 k$ we shall write the fundamental functions $r_{k}(x)$ and $\rho_{k}(x)$ as $r_{k n}(x)$ and $\rho_{k n}(x)$ respectively. Let now $f(x)$ be defined for $[-1,1]$; we consider the sequence of polynomials

$$
R_{n}[x, f]=\sum_{k=1}^{n+2} f\left(x_{k, n}\right) r_{k n}(x)+\sum_{k=2}^{n+1} b_{k n} \rho_{k n}(x) \quad(n \text { even })
$$

We will also prove the convergence theorem in a similar way as obtained by J. Balázs and P. Turán [2].

THEOREM 1.3.1. Let $f(x)$ have a continuous derivative in $[-1,1]$ together with $f^{\prime}(x) \in \operatorname{Lip} \alpha, \alpha>1 / 2$. Further let

$$
\left|b_{k n}\right|=o\left(\frac{n^{1 / 2}}{1-x_{k, n}^{2}}\right), \quad k=2,3, \cdots, n+1,
$$

then the sequence of interpolatory polynomials $R_{n}[x, f]$ as defined in (1.3.6) converges uniformly to $f(x)$ in $[-1,1]$. The class $f^{\prime}(x) \in \operatorname{Lip} \alpha, \alpha>1 / 2$ cannot be replaced by $f^{\prime}(x) \in \operatorname{Lip} 1 / 2$ even if all $b_{k n}$ are zero.

2. 1. The explicit forms of the fundamental polynomials were stated without proof in our earlier work [14]. Here we will state these fundamental polynomials with proof.

THEOREM 2.1.1. The explicit forms of the fundamental polynomials are as follows.

(a) For $k=2,3, \cdots, n+1$ we have 


$$
\rho_{k}(x)=\frac{\left(1-x^{2}\right) u_{n}(x) q_{n-1}(x)}{2 u_{n}^{\prime}\left(x_{k}\right)}
$$

where $q_{n-1}(x)$ is a polynomial in $x$ of degree $\leqq n-1$ which depends on $k$ also and is given by

$$
\left(1-x^{2}\right)^{1 / 4} q_{n-1}(x)=A_{k} \int_{1}^{x} u_{n}(t) w(t) d t+\int_{1}^{x} l_{k}(t) w(t) d t,
$$

$$
A_{k} \int_{-1}^{1} u_{n}(t) w(t) d t=-\int_{-1}^{1} l_{k}(t) w(t) d t
$$

(b) For $k=2,3, \cdots, n+1$ we have

$$
r_{k}(x)=\frac{\left(1-x^{2}\right) l_{k}^{2}(x)}{1-x_{k}^{2}}+\frac{\left(1-x^{2}\right) u_{n}(x) s_{n-1}(x)}{2\left(1-x_{k}^{2}\right) u_{n}^{\prime}\left(x_{k}\right)}+B_{k} \rho_{k}(x)
$$

where $s_{n-1}(x)$ is a polynomial in $x$ of degree $\leqq n-1$ which depends on $k$ also and is given by

$$
\begin{gathered}
\left(1-x^{2}\right)^{1 / 4} s_{n-1}(x)=A_{k}^{\prime} \int_{-1}^{x} u_{n}(t) w(t) d t+\int_{-1}^{x} p_{k}(t) w(t) d t \\
A_{k}^{\prime} \int_{-1}^{1} u_{n}(t) w(t) d t=-\int_{-1}^{1} p_{k}(t) w(t) d t \\
p_{k}(t)=\left(1-t^{2}\right) l_{k}^{\prime \prime}(t)-3 t l_{k}^{\prime}(t)+n(n+2) l_{k}(t) \\
B_{k}=\frac{22 x_{k}^{2}-7}{\left(1-x_{k}^{2}\right)^{2}} .
\end{gathered}
$$

Lastly

(2.1.10) $\quad r_{1}(x)=\frac{u_{n}(x)}{10(n+1)^{2}}\left[5(1+x) u_{n}(x)-2\left(1-x^{2}\right) u_{n}^{\prime}(x)-5\left(1-x^{2}\right) t_{n-2}(x)\right]$

(2.1.11) $\quad r_{n+2}(x)=\frac{u_{n}(x)}{10(n+1)^{2}}\left[5(1-x) u_{n}(x)+2\left(1-x^{2}\right) u_{n}^{\prime}(x)-5\left(1-x^{2}\right) t_{n-2}(x)\right]$ 
where $t_{n-2}(x)$ is a polynomial in $x$ of degree $\leqq n-2$ and is given by

$$
\left(1-x^{2}\right)^{1 / 4} t_{n-2}(x)=\int_{1}^{x} u_{n}^{\prime}(t) w(t) d t
$$

2. 2. In order to prove the above theorem we will require the following Lemmas.

LEMMA 2.2.1. For $x=\cos \theta$ we have

$$
\int_{-1}^{x} u_{2 r}(t) w(t) d t=c_{r} \int_{-1}^{x} w(t) d t+\left(1-x^{2}\right)^{1 / 4} h_{2 r-1}(x), \quad r=1,2,
$$

where

$$
w(t)=\left(1-t^{2}\right)^{-3 / 4}, \quad c_{r} \int_{-1}^{1} w(t) d t=\int_{-1}^{1} u_{2 r}(t) w(t) d t
$$

and $h_{2 r-1}(x)$ is a polynomial of degree $\leqq 2 r-1$ in $x$.

PROOF. This follows from the recurrence relation

$$
\begin{aligned}
(r- & \left.\frac{1}{4}\right) \int_{-1}^{x} u_{2 r}(t) w(t) d t \\
& =\left(r+\frac{1}{4}\right) \int_{-1}^{x} u_{2 r-2}(t) w(t) d t+\left(1-x^{2}\right)^{1 / 4} u_{2 r-1}(x), \quad r=1,2, \cdots
\end{aligned}
$$

Here, as usual $u_{2 r}(x)$ denote the Tchebycheff polynomials of the second kind.

LEMMA 2.2.2. For $x=\cos \theta$ we have

$$
\int_{-1}^{x} u_{2 r-1}(t) w(t) d t=\left(1-x^{2}\right)^{1 / 4} m_{2 r-2}(x), \quad r=1,2, \cdots
$$

where $m_{2 r-2}(x)$ is a polynomial in $x$ of degree $\leqq 2 r-2$.

PROOF. This follows from the recurrence relation

$$
\begin{array}{r}
\left(r-\frac{3}{4}\right) \int_{-1}^{x} u_{2 r-1}(t) w(t) d t-\left(r-\frac{1}{4}\right) \int_{-1}^{x} u_{2 r-3}(t) w(t) d t \\
=\left(1-x^{2}\right)^{1 / 4} u_{2 r-2}(x), \quad r=1,2, \cdots
\end{array}
$$


LEMMA 2.2.3. For $x=\cos \theta, k=2,3, \cdots, n+1$ we have

$$
\int_{-1}^{x} l_{k}(t) w(t) d t=d_{k} \int_{-1}^{x} w(t) d t+\left(1-x^{2}\right)^{1 / 4} e_{n-1}(x)
$$

where

$$
l_{k}(t)=\frac{u_{n}(t)}{\left(t-x_{k}\right) u_{n}^{\prime}\left(x_{k}\right)}, \quad d_{k} \int_{-1}^{1} w(t) d t=\int_{-1}^{1} l_{k}(t) w(t) d t
$$

and $e_{n-1}(x)$ is a polynomial in $x$ of degree $\leqq n-1$.

Proof. This is an easy consequence of formula (2.2.1), (2.2.3) and a well known result of L. Fejér [9]

$$
l_{k}(t)=\frac{2\left(1-x_{k}^{2}\right)}{n+1} \sum_{r=0}^{n} u_{r}\left(x_{k}\right) u_{r}(t), \quad k=2,3, \cdots, n+1
$$

For $r$ even we use Lemma 2.2.1 and for $r$ odd we use Lemma 2.2.2.

2. 3. Here we will give the proof for the determination of the fundamental polynomials of the second kind. In view of uniqueness theorem stated on page 345 as theorem 4 in [14], it remains to verify that the fundamental functions are polynomials of degree $\leqq 2 n+1$ and satisfy the following conditions :

$$
\rho_{k}\left(x_{j}\right)=0, \quad j=1,2, \cdots, n+2, k=2,3, \cdots, n+1
$$

and

$$
\rho_{k}^{\prime \prime}\left(x_{j}\right)=\left\{\begin{array}{ll}
1 & j=k \\
0 & j \neq k
\end{array} \quad j, k=2,3, \cdots, n+1 .\right.
$$

Consider the function

$$
\chi_{k}(x)=\frac{\left(1-x^{2}\right) u_{n}(x) q_{n-1}(x)}{2 u_{n}^{\prime}\left(x_{k}\right)} \quad k=2,3, \cdots, n+1
$$

where for $k=2,3, \cdots, n+1$

$$
\left(1-x^{2}\right)^{1 / 4} q_{n-1}(x)=A_{k} \int_{-1}^{x} u_{n}(t) w(t) d t+\int_{-1}^{x} l_{k}(t) w(t) d t,
$$

and 


$$
A_{k} \int_{-1}^{1} u_{n}(t) w(t) d t+\int_{-1}^{1} l_{k}(t) w(t) d t=0, \quad k=2,3, \cdots, n+1
$$

We observe from Lemma 2.2.1, Lemma 2.2.3 and formula (2.3.5) that $q_{n-1}(x)$ defined by (2.4.4) is indeed a polynomial in $x$ of degree $\leqq n-1$. It is obvious that

$$
\chi_{k}\left(x_{j}\right)=0, \quad j=1,2, \cdots, n+2, k=2,3, \cdots, n+1 .
$$

On differentiating once with respect to $x$ equation (2.3.4) and putting $x=x_{j}$, $j=2,3, \cdots, n+1$ we have

$$
2\left(1-x_{j}^{2}\right) q_{n-1}^{\prime}\left(x_{j}\right)-x_{j} q_{n-1}\left(x_{j}\right)=\left\{\begin{array}{ll}
0 & j \neq k \\
2 & j=k
\end{array}, \quad j, k=2,3, \cdots, n+1\right.
$$

A simple computation gives us

$$
\left[\left(1-x^{2}\right) u_{n}(x)\right]_{x=x_{j}}^{\prime \prime}=-x_{j} u_{n}^{\prime}\left(x_{j}\right), \quad j=2,3, \cdots, n+1
$$

and

$$
\left[\left(1-x^{2}\right) u_{n}(x)\right]_{x=x_{j}}^{\prime}=\left(1-x_{j}^{2}\right) u_{n}^{\prime}\left(x_{j}\right), \quad j=2,3, \cdots, n+1 .
$$

Here dash indicates differentiation with respect to $x$. From (2.3.3), (2.3.7), (2.3.8) and (2.3.9) we get

$$
\chi_{k}^{\prime \prime}\left(x_{j}\right)=\left\{\begin{array}{ll}
1 & j=k \\
0 & j \neq k
\end{array} \quad j, k=2,3, \cdots, n+1 .\right.
$$

Thus we have shown that $\chi_{k}(x)$ is a polynomial in $x$ of degree $\leqq 2 n+1$ and satisfies conditions (2.3.6) and (2.3.10). Therefore we conclude in view of the remark stated earlier

$$
\rho_{k}(x) \equiv \chi_{k}(x)
$$

2. 4. Here we will give the determination of $r_{k}(x)$. Again, in view of the uniqueness theorem [14] it remains to verify that the fundamental functions $r_{k}(x)$ are polynomials of degree $\leqq 2 n+1$ and satisfy the following conditions, i.e.,

$$
r_{k}\left(x_{j}\right)=\left\{\begin{array}{ll}
1 & j=k \\
0 & j \neq k
\end{array} \quad j, k=1,2, \cdots, n+2\right.
$$




$$
r_{k}^{\prime \prime}\left(x_{j}\right)=0 \quad j, k=2,3, \cdots, n+1 .
$$

We need the following lemmas.

LEMMA 2.4.1. Let $x=\cos \theta, k=2,3, \cdots, n+1$, we have

$$
\int_{-1}^{x} p_{k}(t) w(t) d t=f_{k} \int_{-1}^{x} w(t) d t+\left(1-x^{2}\right)^{1 / 4} d_{n-2}(x)
$$

where $d_{n-2}(x)$ is a polynomial in $x$ of degree $\leqq n-2$. Here

$$
f_{k} \int_{-1}^{1} w(t) d t=\int_{-1}^{1} p_{k}(t) w(t) d t
$$

and $p_{k}(t)$ is a polynomial in $t$ of degree $\leqq n-1$, given by

$$
\begin{aligned}
p_{k}(t) & =\left(1-t^{2}\right) l_{k}^{\prime \prime}(t)-3 t l_{k}^{\prime}(t)+n(n+2) l_{k}(t) \\
& =\frac{2\left(1-x_{k}^{2}\right)}{n+1} \sum_{r=0}^{n-1}(n(n+2)-r(r+2)) u_{r}\left(x_{k}\right) u_{r}(t) .
\end{aligned}
$$

ProOF. We use the above representation of $p_{k}(t)$ (which can be easily seen on using (2.2.8) and the differential equation of $\left.u_{r}(t)\right)$, Lemmas 2.2.1 and 2.2.2.

LEMMA 2.4.2. Let $x=\cos \theta$, then $t_{n-2}(x)$ defined by the relation

$$
\left(1-x^{2}\right)^{1 / 4} t_{n-2}(x)=\int_{-1}^{x} u_{n}^{\prime}(t) w(t) d t \quad(n \text { even })
$$

is a polynomial in $x$ of degree $\leqq n-2$.

PROOF. For $n$ even we have

$$
u_{n}(x)=1+2 \sum_{r=1}^{n / 2} T_{2 r}(x), \quad T_{2 r}(x)=\cos 2 r \theta, \quad \cos \theta=x .
$$

Differentiating (2.4.7) with respect to $x$ and using Lemma 2.2.2, we get the above result.

LEMMA 2.4.3. Let $x=\cos \theta, k=2,3, \cdots, n+1$ then $s_{n-1}(x)$ defined by 


$$
\left(1-x^{2}\right)^{1 / 4} s_{n-1}(x)=A_{k}^{\prime} \int_{-1}^{x} u_{n}(t) w(t) d t+\int_{-1}^{x} p_{k}(t) w(t) d t
$$

with

$$
A_{k}^{\prime} \int_{-1}^{1} u_{n}(t) w(t) d t+\int_{-1}^{1} p_{k}(t) w(t) d t=0
$$

is a polynomial in $x$ of degree $\leqq n-1$.

PROOF. The proof of this Lemma follows at once if we use Lemmas 2.2.1, 2.2.2 and (2.4.9). Here we equated to zero the coefficient of $\int_{-1}^{x} w(t) d t$ obtained from the right-hand side of (2.4.8) which gives us the value of $A_{k}^{\prime}$.

Now let us consider the function

$$
M_{k}(x)=\frac{\left(1-x^{2}\right) l_{k}^{2}(x)}{1-x_{k}^{2}}+\frac{\left(1-x^{2}\right) u_{n}(x) s_{n-1}(x)}{2\left(1-x_{k}^{2}\right) u_{n}^{\prime}\left(x_{k}\right)}+B_{k} \rho_{k}(x)
$$

where $s_{n-1}(x)$ is defined in (2.4.8) and $B_{k}$ is given by

$$
B_{k}=\frac{22 x_{k}^{2}-7}{\left(1-x_{k}^{2}\right)^{2}}
$$

In view of Lemma 2.4 .3 and the fact that $\rho_{k}(x)$ is indeed a polynomial in $x$ of degree $\leqq 2 n+1$, we have $M_{k}(x)$ also a polynomial in $x$ of degree $\leqq 2 n+1$. It is also clear that

$$
M_{k}\left(x_{j}\right)=\left\{\begin{array}{lll}
1 & j=k & j=1,2, \cdots, n+2 \\
0 & j \neq k & k=2,3, \cdots, n+1
\end{array}\right.
$$

A simple computation shows that

$$
\left[\frac{\left(1-x^{2}\right) l_{k}^{2}(x)}{1-x_{k}^{2}}\right]_{x=x_{j}}^{\prime \prime}=2 \frac{\left(1-x_{j}^{2}\right)}{\left(1-x_{k}^{2}\right)}\left[l_{k}^{\prime}\left(x_{j}\right)\right]^{2}, \quad j \neq k .
$$

From (2.4.5) we have

(2.4.14) $\quad p_{k}\left(x_{j}\right)=\left(1-x_{j}^{2}\right) l_{k}^{\prime \prime}\left(x_{j}\right)-3 x_{j} l_{k}^{\prime}\left(x_{j}\right)=\frac{-2\left(1-x_{j}^{2}\right) l_{k}^{\prime}\left(x_{j}\right)}{\left(x_{j}-x_{k}\right)}, j \neq k$. 
It can be easily verified that

$$
\left[\left(1-x^{2}\right)^{3 / 4} u_{n}(x)\right]_{x=x_{j}}^{\prime \prime}=0, \quad j=2,3, \cdots, n+1 .
$$

On using (2.4.8), (2.4.15) and (2.4.14) we have

$$
\begin{aligned}
{\left[\left(1-x^{2}\right) u_{n}(x) s_{n-1}(x)\right]_{x=x_{j}}^{\prime \prime} } & =2 u_{n}^{\prime}\left(x_{j}\right) p_{k}\left(x_{j}\right), \quad j \neq k \\
& =\frac{-4\left(1-x_{j}^{2}\right) l_{k}^{\prime}\left(x_{j}\right) u_{k}^{\prime}\left(x_{j}\right)}{\left(x_{j}-x_{k}\right)}, j \neq k .
\end{aligned}
$$

Therefore, from (2.4.10), (2.4.13) and (2.4.16) we get

$$
M_{k}^{\prime \prime}\left(x_{j}\right)=0, \quad j \neq k \quad \text { since } \quad l_{k}^{\prime}\left(x_{j}\right)=\frac{u_{n}^{\prime}\left(x_{j}\right)}{\left(x_{j}-x_{k}\right) u_{n}^{\prime}\left(x_{k}\right)}, j \neq k
$$

Further $B_{k}$ is determined by the fact that

$$
M_{k}^{\prime \prime}\left(x_{k}\right)=0, \quad k=2,3, \cdots, n+1
$$

Thus $M_{k}(x)$ is a polynomial in $x$ of degree $\leqq 2 n+1$ satisfying (2.4.12), (2.4.17) and (2.4.18). Therefore, by the uniqueness theorem

$$
M_{k}(x) \equiv r_{k}(x) \quad k=2,3, \cdots, n+1 .
$$

Proofs for $r_{1}(x), r_{n+2}(x)$ are similar. Here one uses also Lemma 2.4.2.

3. 1. Here we will mention those results concerning Tchebycheff polynomials of second kind which are required for our purpose.

$$
\begin{gathered}
|\sin (p+1) u| \leqq(p+1)|\sin u|,\left|u_{p}(x)\right| \leqq(p+1), \quad-1 \leqq x \leqq 1 \\
\frac{2}{\pi} u \leqq \sin u \leqq u, \quad 0 \leqq u \leqq \frac{\pi}{2} \\
\frac{2}{\pi}(\pi-u) \leqq \sin u \leqq u, \quad-\frac{\pi}{2} \leqq u \leqq \pi
\end{gathered}
$$

For $0 \leqq \theta \leqq \pi / 2$ and on using (3.1.2) we have

$$
\int_{0}^{\theta} \frac{1}{(\sin u)^{1 / 2}} d u \leqq \pi(\sin \theta)^{1 / 2}=\pi\left(1-x^{2}\right)^{1 / 4}, \quad x=\cos \theta
$$

From a well known result of L. Fejér [9] we have 


$$
l_{k}(t)=\frac{2\left(1-x_{k}^{2}\right)}{n+1} \sum_{r=0}^{n} u_{r}\left(x_{k}\right) u_{r}(t), \quad k=2,3, \cdots, n+1
$$

It follows from (3.1.5) on a simple computation (see [9]) that

$$
\left|l_{k}(t)\right| \leqq 2 \text { for }-1 \leqq t \leqq 1
$$

Following recurrence relations are easily verified.

$$
\begin{aligned}
\left(r-\frac{1}{4}\right) \int_{-1}^{1} u_{2 r}(t) w(t) d t=\left(r+\frac{1}{4}\right) \int_{-1}^{1} u_{2 r-2}(t) w(t) d t & \\
r & =1,2, \cdots,
\end{aligned}
$$

$$
\begin{array}{r}
\left(r+\frac{3}{4}\right) \int_{-1}^{1} u_{2 r}(t)\left(1-t^{2}\right)^{1 / 4} d t=\left(r-\frac{3}{4}\right) \int_{-1}^{1} u_{2 r-2}(t)\left(1-t^{2}\right)^{1 / 4} d t \\
r=1,2, \cdots
\end{array}
$$

3.2. Here we will prove certain lemmas which will lead us to the estimation of the fundamental polynomials.

LEMMA 3.2.1. Following estimates are valid.

$$
\int_{-1}^{1} u_{2 r}(t) w(t) d t=4 \sqrt{\pi} \frac{\Gamma\left(r+\frac{5}{4}\right)}{\Gamma\left(r+\frac{3}{4}\right)},
$$

$$
\int_{-1}^{1} u_{2 r}(t)\left(1-t^{2}\right)^{1 / 4} d t=\frac{\sqrt{\pi}}{4} \frac{\Gamma\left(r+\frac{1}{4}\right)}{\Gamma\left(r+\frac{7}{4}\right)},
$$

$$
\begin{aligned}
& \text { (3.2.3) }\left|\int_{1}^{x} u_{p}(t) w(t) d t\right| \leqq \pi(p+1)\left(1-x^{2}\right)^{1 / 4}, 0 \leqq x \leqq 1, \\
& \text { (3.2.4) }\left|\int_{1}^{x} l_{k}(t) w(t) d t\right| \leqq 2 \pi\left(1-x^{2}\right)^{1 / 4}, \quad 0 \leqq x \leqq 1, \quad k=2,3, \cdots, n+1 .
\end{aligned}
$$

PROOF. (3.2.1) and (3.2.2) follow from the recurrence relations (3.1.7) and (3.1.8) respectively. Using (3.1.1) and (3.1.4) we have (3.2.3). Similarly on using (3.1.4) and (3.1.6) we have (3.2.4) immediately. This proves the lemma. When $-1 \leqq x \leqq 0$ then on using (3.1.3) and (3.1.6) we have 
(3.2.3a) $\quad\left|\int_{-1}^{x} u_{p}(t) w(t) d t\right| \leqq \pi(p+1)\left(1-x^{2}\right)^{1 / 4}, \quad-1 \leqq x \leqq 0$

and

$$
\left|\int_{-1}^{x} l_{k}(t) w(t) d t\right| \leqq 2 \pi\left(1-x^{2}\right)^{1 / 4}, \quad-1 \leqq x \leqq 0
$$

LEMMA 3.2.2. Following estimates are valid

$$
\begin{gathered}
\left|\int_{1}^{x} u_{p}(t) w(t) d t\right| \leqq 7(p+1)^{1 / 2}, \quad 0 \leqq x \leqq 1 \\
\left|\int_{1}^{x} l_{k}(t) w(t) d t\right| \leqq \frac{8 \log n}{(n+1) \sin \theta_{k}}+\frac{14}{(n+1)^{1 / 2}}, \\
\quad \text { for } k=2,3, \cdots, n+1 \text { and } 0 \leqq x \leqq 1
\end{gathered}
$$

$$
\left|\int_{-1}^{1} l_{k}(t) w(t) d t\right| \leqq \frac{8 \sqrt{\pi}}{(n+1)} \frac{\Gamma\left(\frac{n}{2}+\frac{5}{4}\right)}{\Gamma\left(\frac{n}{2}+\frac{3}{4}\right)}, \quad k=2,3, \cdots, n+1 .
$$

PROOF. We observe that

(3. 2. 8) $\quad \int_{1}^{x} u_{p}(t) w(t) d t=\int_{0}^{\theta} \frac{\sin (p+1) u}{(\sin u)^{3 / 2}} d u, \quad x=\cos \theta, t=\cos u$.

If $0 \leqq \theta \leqq \pi /(p+1)$ then using (3.1.1) and (3.1.3) we have

(3. 2.9) $\int_{0}^{\theta} \frac{\sin (p+1) u}{(\sin u)^{3 / 2}} d u \leqq(p+1) \int_{0}^{\theta} \frac{1}{(\sin u)^{1 / 2}} d u \leqq \sqrt{2} \pi(p+1)^{1 / 2}$.

In case $\pi /(p+1) \leqq \theta \leqq \pi / 2$ then we have

$$
\int_{0}^{\theta} \frac{\sin (p+1) u}{(\sin u)^{3 / 2}} d u=\int_{0}^{\pi /(p+1)}+\int_{\pi /(p+1)}^{\theta} .
$$

But

(3. 2. 11) $\left|\int_{\pi /(p+1)}^{\theta} \frac{\sin (p+1) u}{(\sin u)^{3 / 2}} d u\right| \leqq \int_{\pi /(p+1)}^{\pi / 2} \frac{1}{(\sin u)^{3 / 2}} d u \leqq\left(\frac{\pi}{2}\right)^{3 / 2} \int_{\pi /(p+1)}^{\pi / 2} u^{-3 / 2} d u$

$$
<\pi 2^{-1 / 2}(p+1)^{1 / 2} \text {. }
$$


Therefore, on using (3.2.8)-(3.2.11) we have

$$
\left|\int_{1}^{x} u_{p}(t) w(t) d t\right| \leqq 2^{1 / 2} \pi(p+1)^{1 / 2}+\pi 2^{-1 / 2}(p+1)^{1 / 2}<7(p+1)^{1 / 2}
$$

from which (3.2.5) follows. In a similar way we can easily prove that

$$
\left|\int_{1}^{x} u_{p}(t)\left(1-t^{2}\right)^{1 / 4} d t\right| \leqq \frac{4}{p+1}
$$

As a consequence of $(3.1 .5)$ and (3.2.12) we have

$$
\left|\int_{1}^{x} l_{k}(t)\left(1-t^{2}\right)^{1 / 4} d t\right| \leqq \frac{8 \log n}{(n+1)}\left(1-x_{k}^{2}\right)^{1 / 2} .
$$

But we know that

$$
\begin{aligned}
& \int_{1}^{x} l_{k}(t) w(t) d t \\
& \quad=\left(1-x_{k}^{2}\right)^{-1}\left[\int_{1}^{x} l_{k}(t)\left(1-t^{2}\right)^{1 / 4} d t+\frac{1}{u_{n}^{\prime}\left(x_{k}\right)} \int_{1}^{x} \frac{\left(t+x_{k}\right) u_{n}(t)}{\left(1-t^{2}\right)^{3 / 4}} d t\right]
\end{aligned}
$$

On using (3.2.5) and (3.2.13) we have

$$
\left|\int_{1}^{x} l_{k}(t) w(t) d t\right| \leqq \frac{8 \log n}{(n+1) \sin \theta_{k}}+14(n+1)^{-1 / 2}
$$

which proves (3.2.6). Proof of (3.2.7) follows from (3.1.5) and (3.2.1) and on using Abel's lemma.

3. 3. The above two lemmas lead us to formulate the estimation of the fundamental polynomials of the second kind. First we observe as a consequence of (2.1.3), (3.2.1) and (3.2.7) we have

$$
\left|A_{k}\right| \leqq \frac{2}{n+1}, \quad k=2,3, \cdots, n+1 .
$$

On using (3.2.5), (3.2.6), (3.3.1) and (2.1.2) we have

$$
\left|\left(1-x^{2}\right)^{1 / 4} q_{n-1}(x)\right| \leqq \frac{28}{(n+1)^{1 / 2}}+\frac{8 \log n}{(n+1) \sin \theta_{k}}, \quad k=2,3, \cdots, n+1
$$


Similarly from (2.1.2), (3.3.1), (3.2.3) and (3.2.4) we have

$$
\left|q_{n-1}(x)\right| \leqq \frac{2}{n+1} \pi(n+1)+2 \pi=4 \pi .
$$

Now we prove

LEMMA 3.3.1. For $-1 \leqq x \leqq 1$ we have

$$
\begin{aligned}
& \frac{\left|\rho_{k}(x)\right|}{1-x_{k}^{2}} \leqq \frac{14}{(n+1)^{3 / 2}}+\frac{4 \log n}{(n+1)^{2} \sin \theta_{k}}, \quad k=2,3, \cdots, n+1 \\
& \sum_{k=2}^{n+1} \frac{\left|\rho_{k}(x)\right|}{1-x_{k}^{2}} \leqq 26(n+1)^{-1 / 2}
\end{aligned}
$$

and

$$
\frac{\left|\rho_{k}^{\prime}(x)\right|}{1-x_{k}^{2}} \leqq 12, \quad \sum_{k=2}^{n+1} \frac{\left|\rho_{k}^{\prime}(x)\right|}{1-x_{k}^{2}} \leqq 12 n
$$

PROOF. We will obtain the estimates for $0 \leqq x \leqq 1$, similarly it holds for $-1 \leqq x \leqq 0$. For in view of (2.1.3) we can also write $\rho_{k}(x)$ in the form

$$
\rho_{k}(x)=\frac{\left(1-x^{2}\right)^{1 / 2} u_{n}(x)}{2 u_{n}^{\prime}\left(x_{k}\right)}\left[A_{k} \int_{-1}^{x} u_{n}(t) w(t) d t+\int_{-1}^{x} l_{k}(t) w(t) d t\right]
$$

From (2.1.1) and (3.3.2) we have immediately (3.3.4) and (3.3.5). From (2.1.1) and (2.1.2) we have

$$
\begin{aligned}
\rho_{k}^{\prime}(x)=\frac{1}{2 u_{n}^{\prime}\left(x_{k}\right)}\left[-\left\{(n+1) T_{n+1}(x)\right.\right. & \left.+\frac{x}{2} u_{n}(x)\right\} q_{n-1}(x) \\
& \left.+A_{k} u_{n}^{2}(x)+u_{n}(x) l_{k}(x)\right],
\end{aligned}
$$

on using (3.3.3), (3.1.1), (3.3.1) and (3.1.6) we have

$$
\frac{\left|\rho_{k}^{\prime}(x)\right|}{1-x_{k}^{2}} \leqq \frac{1}{2(n+1)}\left[\frac{3(n+1)}{2} 4 \pi+\frac{2}{(n+1)}(n+1)^{2}+2(n+1)\right] \leqq 12,
$$

from which (3.3.6) follow.

3. 4. The object here is to prove that the estimation that we have obtained in Lemma 3.3.1 is best possible in a certain sense. 
LEMMA 3.4.1. There exists a positive number $c_{1}$ and $c_{2}$ such that for $n>n_{0}$

$$
\sum_{i=2}^{n+1} \frac{\left|\rho_{i}(0)\right|}{1-x_{i}^{2}} \geqq c_{1} n^{-1 / 2}
$$

and

$$
\sum_{i=2}^{n+1} \frac{\left|\rho_{i}^{\prime}(1)\right|}{1-x_{i}^{2}} \geqq c_{2} n
$$

PROOF. From (2.1.1) and (2.1.2) we have

$$
\frac{\left|\rho_{k}(0)\right|}{1-x_{k}^{2}}=\frac{1}{4(n+1)}\left|\int_{0}^{1} \phi_{k}(t) w(t) d t\right|
$$

where

$$
\boldsymbol{\varphi}_{k}(t)=l_{k}(t)-l_{k}(-t)=\frac{4\left(1-x_{k}^{2}\right)}{n+1} \sum_{r=1}^{n / 2} u_{2 r-1}\left(x_{k}\right) u_{2 r-1}(t)
$$

First we note that owing to (3.4.4) and (3.2.12) we have immediately

$$
\left|\int_{0}^{1} \phi_{k}(t)\left(1-t^{2}\right)^{1 / 4} d t\right| \leqq \frac{16\left(1-x_{k}^{2}\right)}{n+1} \log n
$$

and a simple computation shows that

$$
\text { (3. 4. 6) } \begin{aligned}
& \int_{0}^{1} u_{n-1}(t) w(t) d t=\frac{1\left(\frac{n}{2}+\frac{3}{4}\right)}{\Gamma\left(\frac{n}{2}+\frac{1}{4}\right)}\left(\frac{2 \Gamma\left(\frac{5}{4}\right)}{\Gamma\left(\frac{7}{4}\right)}+\sum_{j=1}^{n / 2} \frac{\Gamma\left(j-\frac{3}{4}\right)}{\Gamma\left(j+\frac{3}{4}\right)}(-1)^{j+1}\right) \\
& \geqq c_{3} n^{1 / 2}
\end{aligned}
$$

on using (3.4.6) we have

(3. 4. 7) $\quad \int_{0}^{1} 2 t u_{n}(t) w(t) d t=\int_{0}^{1}\left(u_{n+1}(t)^{s}+u_{n-1}(t)\right) w(t) d t \geqq c_{4} n^{1 / 2}$

From the identity

$$
1-x_{k}^{2}=1-t^{2}+t^{2}-x_{k}^{2}
$$


we have

(3. 4. 8) $\quad \int_{0}^{1} \varphi_{k}(t) w(t) d t$

$$
=\left(1-x_{k}^{2}\right)^{-1}\left[\int_{0}^{1} \boldsymbol{\varphi}_{k}(t)\left(1-t^{2}\right)^{1 / 4} d t+\frac{2}{u_{n}^{\prime}\left(x_{k}\right)} \int_{0}^{1} t u_{n}(t) w(t) d t\right] .
$$

Therefore, on using (3.4.7), (3.4.3) and (3.4.5) we have

$$
\begin{aligned}
\sum_{k=2}^{n+1} \frac{\left|\rho_{k}(0)\right|}{1-x_{k}^{2}} & \geqq \sum_{k=[n / 8]}^{[n / 4]} \frac{\left|\rho_{k}(0)\right|}{1-x_{k}^{2}} \\
& \geqq \frac{1}{4(n+1)}\left[\frac{c_{4} n^{1 / 2}}{(n+1)} \frac{n}{4}-\frac{16}{(n+1)} \log n \sum_{k=[n / 8]}^{[n / 4]} \frac{1}{\sin \theta_{k}}\right] \\
& \geqq c_{5} n^{-1 / 2}-\frac{4 \log n}{(n+1)^{2}} \frac{3 n}{4} \geqq c_{1} n^{-1 / 2} \text { for } n \geqq n_{0} .
\end{aligned}
$$

This completes the proof of (3.4.1). In order to prove (3.4.2) we use (3.3.7) and we get

(3. 4.9) $\frac{\left|\rho_{k}(1)\right|}{1-x_{k}^{2}}=2\left|(n+1) A_{k}+l_{k}(1)\right|=2\left|(n+1) A_{k}+(-1)^{k-1}\left(1+x_{k}\right)\right|$.

On using (2.1.3), (3.2.1) and (3.1.5) we have

$$
\begin{aligned}
& (n+1) A_{k}+(-1)^{k+1} x_{k} \\
& \quad=\frac{-\Gamma\left(\frac{n}{2}+\frac{3}{4}\right)}{\Gamma\left(\frac{n}{2}+\frac{5}{4}\right)}\left(\frac{\Gamma\left(\frac{5}{4}\right)}{\Gamma\left(\frac{3}{4}\right)}+\frac{1}{2} \sum_{r=1}^{n / 2} \frac{\Gamma\left(r+\frac{1}{4}\right)}{\Gamma\left(r+\frac{3}{4}\right)} \cos 2 r \theta_{k}\right) .
\end{aligned}
$$

Using Abel's Lemma we have

(3. 4. 11) $\left|(n+1) A_{k}+(-1)^{k+1} x_{k}\right| \leqq c_{6} n^{-1 / 2}\left(\sin \theta_{k}\right)^{-1}, \quad k=2,3, \cdots, n+1$.

From (3.4.9) and (3.4.11) we have 
282

A. K. VARMA

$$
\begin{aligned}
\sum_{k=2}^{n+1} \frac{\left|\rho_{k}^{\prime}(1)\right|}{1-x_{k}^{2}} & \geqq \sum_{k=[n / 8]}^{[n / 4]} \frac{\left|\rho_{k}^{\prime}(1)\right|}{1-x_{k}^{2}} \geqq \frac{n}{4}-c_{6} n^{-1 / 2} \sum_{k=[n / 8]}^{[n / 4]}\left(\sin \theta_{k}\right)^{-1} \\
& \geqq \frac{n}{4}-c_{7} n^{1 / 2} \geqq c_{2} n,
\end{aligned}
$$

which proves (3.4.2).

4. 1. Here we shall prove lemmas which will lead to the estimates of the fundamental polynomials of the first kind.

LEMMA 4.1.1. We have

$$
\sum_{k=2}^{n+1} \frac{\left(1-x^{2}\right) l_{k}^{2}(x)}{1-x_{k}^{2}} \leqq 2
$$

$$
\int_{1}^{x} u_{n}^{\prime}(t) w(t) d t \leqq 14 n^{5 / 2}, \quad 0 \leqq x \leqq 1
$$

$$
\left|\int_{1}^{x} p_{k}(t) w(t) d t\right| \leqq 55(n+1)^{3 / 2}, \quad 0 \leqq x \leqq 1, k=2,3, \cdots, n+1 \text {, }
$$

(4. 1. 4) $\left|\int_{1}^{x} p_{k}(t) w(t) d t\right| \leqq 3 \pi(n+1)^{2}\left(1-x^{2}\right)^{1 / 4}, \quad 0 \leqq x \leqq 1, k=2,3, \cdots, n+1$,

$$
\left|\int_{-1}^{1} p_{k}(t) w(t) d t\right| \leqq 8 \sqrt{\pi}(n+1) \frac{\Gamma\left(\frac{n}{2}+\frac{5}{4}\right)}{\Gamma\left(\frac{n}{2}+\frac{3}{4}\right)},
$$

where $p_{k}(t)$ is defined by (2.1.8). and

Proof. (4.1.1) is due to P.Szasz [10]. (4.1.2) follows from (3.2.5)

$$
u_{n}^{\prime}(t)=4 \sum_{j=1}^{n / 2} j u_{2 j-1}(t) \quad(n \text { even })
$$

Using (3.1.6) and Markov and Bernstein inequalities we have

$$
\left|l_{k}^{\prime}(x)\right| \leqq 2 n^{2}, \quad\left|l_{k}^{\prime}(x)\right| \leqq \frac{2 n}{\left(1-x^{2}\right)^{1 / 2}}
$$


respectively. Exactly in the way I proved (3.2.5) we have on using (4.1.7)

$$
\left|\int_{1}^{x} \frac{t l_{k}^{\prime}(t)}{\left(1-t^{2}\right)^{3 / 4}} d t\right| \leqq 8 n^{3 / 2}, \quad k=2,3, \cdots, n+1,0 \leqq x \leqq 1
$$

From (2.1.8) and integration by parts we have

$$
\int_{1}^{x} p_{k}(t) w(t) d t=\left(1-x^{2}\right)^{1 / 4} l_{k}^{\prime}(x)-\frac{7}{2} \int_{1}^{x} t l_{k}^{\prime}(t) w(t) d t+n(n+2) \int_{1}^{x} l_{k}(t) w(t) d t
$$

Now using (4.1.7), (4.1.8) and (3.2.6) we have

$$
\left|\int_{1}^{x} p_{k}(t) w(t) d t\right| \leqq 2 n^{3 / 2}+28 n^{3 / 2}+25 n^{3 / 2}=55 n^{3 / 2}
$$

This proves (4.1.3). A simple computation shows that

$$
\left|p_{k}(t)\right| \leqq 3(n+1)^{2}, \quad k=2,3, \cdots, n+1 .
$$

Therefore on using (3.1.4) we have

(4.1.10) $\quad \int_{1}^{x} p_{k}(t) w(t) d t \leqq 3(n+1)^{2} \int_{1}^{x} w(t) d t \leqq 3 \pi(n+1)^{2}\left(1-x^{2}\right)^{1 / 4}$

This proves (4.1.4). Proof of (4.1.5) follows from another representation of $p_{k}(t)$ and (3.2.1),

$$
p_{k}(t)=\frac{2\left(1-x_{k}^{2}\right)}{n+1} \sum_{r=0}^{n} \alpha_{r} u_{r}(t) u_{r}\left(x_{k}\right)
$$

with $\alpha_{r}=n(n+2)-r(r+2)$. This proves the lemma. As a consequence of the above lemma we have from (2.1.7), (3.2.1) and (4.1.5)

$$
\left|A_{k}^{\prime}\right| \leqq 2(n+1) \text {. }
$$

Also on using (2.1.6), (4.1.12), (3.2.5) and (4.1.3) we get

$$
\left|\left(1-x^{2}\right)^{1 / 4} s_{n-1}(x)\right| \leqq 14(n+1)^{3 / 2}+55(n+1)^{3 / 2}=69(n+1)^{3 / 2} .
$$

Similarly from (4.1.4), (2.1.6), (4.2.3) and (3.2.3) we have 


$$
\left|s_{n-1}(x)\right| \leqq 2 \pi(n+1)^{2}+3 \pi(n+1)^{2}=5 \pi(n+1)^{2} .
$$

4.2. Here we shall give an estimate of the fundamental polynomials of the first kind.

LEMMA 4.2.1. For $-1 \leqq x \leqq 1$ we have

$$
\begin{gathered}
\sum_{k=2}^{n+1}\left|r_{k}(x)\right| \leqq 48 n^{3 / 2}, \\
\left|r_{1}(x)\right| \leqq 9 n^{1 / 2}, \quad\left|r_{n+2}(x)\right| \leqq 9 n^{1 / 2} \\
\left|r_{1}^{\prime}(x)\right| \leqq 18 n^{5 / 2}, \quad\left|r_{n+2}^{\prime}(x)\right| \leqq 18 n^{5 / 2}
\end{gathered}
$$

Proof. On using (2.1.10), (3.1.1) and (4.1.2) we have

$$
\left|r_{1}(x)\right| \leqq \frac{1}{10(n+1)^{2}}\left[10(n+1)^{2}+4(n+1)^{2}+70 n^{5 / 2}\right] \leqq 9 n^{1 / 2}
$$

(4.2.3) follows from (4.2.2) on using Markov's inequality. (4.2.1) follows from (2.1.9), (3.3.4), (4.1.1) and (4.1.13). This proves the lemma.

LEMMA 4.2.2. For $-1 \leqq x \leqq 1$ we have

$$
\sum_{k=2}^{n+1}\left|r_{k}^{\prime}(x)\right| \leqq 55 n^{3}
$$

PROOF. From (4.1.1) and Schwarz inequality we have

$$
\sum_{k=2}^{n+1} \frac{\left(1-x^{2}\right)^{1 / 2}\left|l_{k}(x)\right|}{1-x_{k}^{2}} \leqq 4(n+1)
$$

Therefore on using (4.1.7) and (4.2.5) we obtain

$$
\sum_{k=2}^{n+1}\left|\frac{\left[\left(1-x^{2}\right) l_{k}^{2}(x)\right]^{\prime}}{1-x_{k}^{2}}\right| \leqq 12(n+1)^{2}
$$

From (2.1.9) and (3.3.6) we have

$$
\sum_{k=2}^{n+1}\left|B_{k} \rho_{k}^{\prime}(x)\right| \leqq 180 \sum_{k=2}^{n+1} \frac{1}{1-x_{k}^{2}} \leqq 90(n+1)^{2} .
$$


On using (2.1.6), (4.1.14), (4.1.12) and (4.1.9) we have

$$
\begin{aligned}
{\left[\left(1-x^{2}\right) u_{n}(x) s_{n-1}(x)\right]^{\prime}=} & -\left[(n+1) T_{n+1}(x)+(x / 2) u_{n}(x)\right] s_{n-1}(x) \\
& +u_{n}^{2}(x) A_{k}^{\prime}+u_{n}(x) p_{k}(x) .
\end{aligned}
$$

So we get

$$
\left|\left[\left(1-x^{2}\right) u_{n}(x) s_{n-1}(x)\right]^{\prime}\right| \leqq 24(n+1)^{3}+5(n+1)^{3}=29(n+1)^{3} .
$$

Now (4.2.4) follows from (4.2.6), (4.2.2), (2.1.5) and (4.2.8).

4.3. Here we will prove that the estimates obtained in Lemmas 4.2.1 and 4.2 .2 are best possible in a certain sense.

LEMMA 4.3.1. There exist positive constants $c_{6}$ and $c_{7}$ such that

$$
\sum_{k=2}^{n+1}\left|r_{k}(0)\right| \geqq c_{6} n^{3 / 2}
$$

and

$$
\sum_{k=2}^{n+1}\left|r_{k}^{\prime}(1)\right| \geqq c_{7} n^{3}
$$

for $n \geqq n_{1}$.

PROOF. From (2.1.5), (4.1.1) and (3.3.4) we have

$$
\sum_{k=2}^{n+1}\left|r_{k}(0)\right| \geqq \sum_{k=[n / 8]}^{[n / 4]}\left|r_{k}(0)\right| \geqq \frac{n+1}{2} \sum_{k=[n / 8]}^{[n / 4]}\left|s_{n-1}(0)\right|-2-c_{8} n,
$$

on using (2.1.6) and (2.1.7) we have

$$
s_{n-1}(0)=-\frac{1}{2} \int_{0}^{1} x_{k}(t) w(t) d t,
$$

where

(4. 3. 5) $\quad x_{k}(t)=p_{k}(t)-p_{k}(-t)=\frac{4\left(1-x_{k}^{2}\right)}{n+1} \sum_{r=1}^{n / 2} \alpha_{2 r-1} u_{2 r-1}\left(x_{k}\right) u_{2 r-1}(t)$.

Almost in a similar way as we proved (3.4.1) it follows that

$$
\sum_{k=[n / 8]}^{[n / 4]}\left|s_{n-1}(0)\right| \geqq c_{9} n^{5 / 2},
$$


using (4.3.3) and (4.3.6), (4.3.1) follows. The proof for (4.3.2) is similar as given for (3.4.2). Here we use (4.2.6), (4.2.7) and similar result as given in (3.4.10). This proves the lemma.

5. 1. These lemmas proved above lead us easily to prove our main Theorems 1.2.1 and 1.3.1. First we shall prove Theorem 1.2.1. Owing to the uniqueness theorem we can write any arbitrary polynomial of degree $\leqq 2 n+1$ in the form

$$
Q_{2 n+1}(x)=\sum_{k=1}^{n+2} Q_{2 n+1}\left(x_{k}\right) r_{k}(x)+\sum_{k=2}^{n+1} Q_{2 n+1}^{\prime \prime}\left(x_{k}\right) \rho_{k}(x)
$$

Now (1.2.3) follows from (4.2.1), (3.3.5), (1.2.1) and (1.2.2). That (1.2.3) is essentially best possible can be shown by the polynomial

$$
f_{0}(x)=\sum_{k=1}^{n+2} A \operatorname{sign} r_{k}(0) r_{k}(x)+\sum_{k=2}^{n+1} \frac{B \operatorname{sign} \rho_{k}(0)}{1-x_{k}^{2}} \rho_{k}(x)
$$

at $x=0$. Here we use (3.4.1) and (4.3.1). Again (1.2.4) follows from (5.1.1), (1.2.1). (1.2.2), (3.3.6), (4.2.3) and (4.2.4). That (1.2.4) is essentially best possible is shown by the polynomial

$$
f_{1}(x)=\sum_{k=1}^{n+2} A \operatorname{sign} r_{k}^{\prime}(x)+\sum_{k=2}^{n+1} \frac{B \operatorname{sign} \rho_{k}^{\prime}(1)}{1-x_{k}^{2}} \rho_{k}^{\prime}(x)
$$

at $x=1$. This follows from (3.4.2) and (4.3.2). This completes the proof of Theorem 1.2.1.

Proof OF THEOREM 1.3.1. Here we follow the notations given in section 1.3. From the uniqueness theorem it follows that any polynomial $\boldsymbol{\varphi}_{n}(x)$ of degree $\leqq 2 n+1$ can be written in the form

$$
\varphi_{n}(x)=\sum_{k=1}^{n+2} \phi_{n}\left(x_{k, n}\right) r_{k n}(x)+\sum_{k=2}^{n+1} \phi_{n}^{\prime \prime}\left(x_{k, n}\right) \rho_{k n}(x) .
$$

We have from (1.3.6)

$$
R_{n}(x, f)=R_{n}(x)=\sum_{k=1}^{n+2} f\left(x_{k, n}\right) r_{k n}(x)+\sum_{k=2}^{n+1} b_{k n} \rho_{k n}(x)
$$

From Lemma 8.2 of my earlier work [13] it follows that under the conditions 
of Theorem 1.3.1 there exists a sequence of polynomials $\phi_{n}(x)$ of degree $\leqq n$ such that

$$
\left|f(x)-\boldsymbol{\phi}_{n}(x)\right|=O\left(n^{-1-\alpha}\right)\left[\left(1-x^{2}\right)^{\frac{1+\alpha}{2}}+n^{-1-\alpha}\right], \quad 0<\alpha<1,
$$

and

$$
\left|\boldsymbol{\varphi}_{n}^{\prime \prime}\left(x_{k, n}\right)\right| \leqq c_{8} n^{1-\alpha}\left(1-x_{k, n}^{2}\right)^{\frac{\alpha-1}{2}}
$$

Now writing

$$
f(x)-R_{n}(x)=f(x)-\phi_{n}(x)+\varphi_{n}(x)-R_{n}(x) .
$$

On using (5.1.4), (5.1.5) and the estimates of the fundamental polynomials we have at once

$$
\left|\phi_{n}(x)-R_{n}(x)\right|=o(1) \quad \text { for } \quad \alpha>1 / 2 .
$$

From (5.1.6) of course we have

$$
\left|f(x)-\varphi_{n}(x)\right|=o(1) .
$$

Therefore for $\alpha>1 / 2$

$$
\left|f(x)-R_{n}(x)\right|=o(1)
$$

This proves the theorem. Theorem 1.3.1 is essentially best possible follows from (3.4.1), (4.3.1) and using the device given in the paper of P. Erdös and P. Turán [5] entitled on the role of Lebesgue function in the theory of Lagrange interpolation.

\section{REFERENCES}

[1] J. BALÁzs ANd P. TuRÁN, Notes on interpolation II, Acta Math. Acad. Sci. Hungar., 8(1957), 201-215.

[ 2 ] J. BALÁZS AND P. TURÁN, Notes on interpolation III, ibid., 9(1958), 195-214.

[ 3 ] J. BALÁzS AND P. TURÁN, Notes on interpolation IV, ibid., 9(1958), 243-258.

[ 4 ] P. ERDös, Extremal properties of derivatives of polynomials, Annals Math., (2) 41(1940), 310-313.

[5] P. ERDÖS AND P. TURÁN, On the role of Lebesgue function in the theory of Lagrange interpolation, Acta Math. Acad. Sci. Hungar., 6(1955), 47-60.

[6] L.FEJÊR, Die abschätzung eines Polynoms in einem Intervalle, wenn Schranken für seine Werte und ersten Ableitungswerte in einzelnen Punkten des Intervalles gegeben sind, und ihre Anwendung auf die Konvergenzfrage Hermitescher Interpolationsreihen, Math. Z., 32(1930), 426-457.

[ 7 ] E. LANDAU, Einige Ungleichugen für zweimal differenzierbare Funktionen, Proc. London Math. Soc., Ser. 2. 13(1913), 43-49. 
[ 8 ] G. LoRENTZ, Approximation of functions, Holt, Rinehart and Winston, 1966.

[ 9 ] G.SzEGö, Orthongonal polynomials, A.M.S. Colloquium Pub., Vol. 23, 1959.

[10] P.SzÁsz, On quasi Hermite-Fejér interpolation, Acta Math. Acad. Sci. Hungar., 10 (1959), 413-439.

[11] P. TURÁN, Über die Ableitung von Polynomes, Compositio. Math., 7(1939-40), 89-95.

[12] A.K. VARMA, Inequalities for polynomials and their derivatives, Acta Sci. Szeged (Hungary), 29(1968), 137-146.

[13] A. K. VARMA, On a problem of P. Turán on lacunary interpolation, Canad. Math. Bull., $10(1961), 531-551$.

[14] A. K. VARMA AND A. SHARMA, Some interpolatory properties of Tchebycheff polynomials $(0,2)$ case, Publ. Math. Debrecen. (Hungary), 8(1961), 336-349.

DEPARTMENT OF MATHEMATICS

UNIVERSTTY OF ALBERTA

Edmonton, Alberta, CANAdA 